\title{
ANALISIS PENGGUNAAN BAHASA MAHASISWA DAN DOSEN PADA UKM KEPROTOKOLAN SERTA DISKUSI DI KELAS
}

\author{
Lilik Herawati \\ Tadris Bahasa Indonesia, FITK-IAIN Syekh Nurjati; Jl. Perjuangan By Pass Sunyaragi \\ Cirebon 45132, Telp. 0231481264 Fax. 0231 489926) \\ lilikher74@gmail.com
}

\begin{abstract}
ABSTRAK: Bahasa Indonesia merupakan alat pertama, alat utama, dan alat pokok fundamental dalam proses pendidikan. Berbicara tentang pendidikan, erat sekali kaitannya dengan bahasa. Bahasa tanpa penuturnya (mahasiswa dan dosen) tidak akan menghasilkan suatu bahasa, begitu pun penutur tanpa bahasanya tidak akan menciptakan suatu bahasa. Karena bahasa memerlukan penutur dengan bunyi bahasanya yang dituturkan. Erat kaitannya dengan pembinaan yang ditujukan kepada orangnya atau penuturnya kemudian pengembangan yang ditunjukan kepada bahasanya. Kedua hal itu saling berkaitan dan tidak bisa dipisahkan, karena untuk mencetak generasi yang cinta akan bahasa nasional bangsa kita, maka merekalah yang senantiasa meningkatakan mutu pembelajarannya dalam bahasa Indonesia dengan menguasai PUEBI serta melaksanakan Undang-Undang Kebijakan tentang bahasa yang harus kita biasakan bahkan lestarikan. Sehingga Pemerintah harus lebih tegas dan menegakkan tentang hukum ketatabahasaan. Supaya mereka dapat saling membina dan mengembangkan bahasa diduplikasi selanjutnya.

KATA KUNCI: Analisis; bahasa; UKM keprotokolan; dan diskusi.
\end{abstract}

\section{ANALYSIS OF THE USE OF STUDENTS AND LECTURERS IN PROTOCOLAN SME AND CLASS DISCUSSION}

\begin{abstract}
Indonesian language is the first tool, the main tool, and the main fundamental tool in the educational process. Talking about education, it is closely related to language. Language without speakers (students and lecturers) will not produce a language, likewise speakers without language will not create a language. Because language requires speakers with the sounds of the language spoken. Closely related to coaching aimed at the person or speaker, then the development shown in the language. These two things are interrelated and cannot be separated, because in order to create a generation that loves our nation's national language, it is they who always improve the quality of their learning in Indonesian by mastering PUEBI and implementing the Policy Law on language that we must get used to and even preserve. So that the Government must be more firm and enforce grammatical law. So that they can foster each other and develop language in the next duplication.

KEYWORDS: Analysis; language; protocol UKM; and discussion.

\begin{tabular}{lccc}
\hline Diterima: & Direvisi: & Distujui: & Dipublikasi: \\
24-09-2020 & 06-10-2020 & $06-10-2020$ & $28-10-2020$ \\
Pustaka & $:$ Herawati, L. (2020). Analisis Penggunaan Bahasa Mahasiswa Dan Dosen Pada UKM \\
& Keprotokolan Serta Diskusi di Kelas. Fon $:$ Jurnal Pendidikan Bahasa dan Sastra Indonesia, \\
& 16(2), 145-152. & \\
DOI $\quad:$ https://doi.org/10.25134/fjpbsi.v16i2.3507 & \\
\hline
\end{tabular}
\end{abstract}

\section{PENDAHULUAN}

Pembinaan dan pengembangan bahasa merupakan usaha dan kegiatan yang dilakukan untuk memelihara dan mengembangkan bahasa Indonesia, supaya dapat memenuhi fungsi dan kedudukannya.

Bahasa Indonesia merupakan alat pertama dan utama untuk membangun arus pemikiran yang jelas dan teliti. Jadi bahasa Indonesia sebagai alat komunikasi. Bahasa Indonesia merupakan alat pertama, alat utama, dan alat pokok fundamental dalam proses pendidikan. Berbicara tentang pendidikan, erat sekali kaitannya dengan bahasa, tanpa bahasa pendidikan pun tidak akan tersampaikan seperti dalam keprotokoleran, proses diskusi bahkan dalam proses pembelajaran yang semua itu ada kaitannya dengan 
penuturnya baik itu remaja maupun dewasa. Sesuai dengan titik fokus peneliti yaitu mahasiswa dan dosen IAIN Syekh Nurjati Cirebon.

Mengapa demikian? Karena hal tersebut semakin lumrah dapat kita temukan di kehidupan sehari-hari, bahasa yang dituturkan para mahasiswa bahkan dosen sekalipun kurang sesuai dengan kaidah ketatabahasaan bahkan di area formal pun mereka sering menyelipkan penggunaan bahasa Indonesia tersebut dengan bahasa daerahnya, bahasa asing bahkan bahasa ragam gaulnya yang memang hal itu melanggar aturan kebahasaan. Padahal UU no. 20 tahun 2003 mengenai penerapan pengajaran bahasa Indonesia dan UU no. 24 tahun 2009 BAB III pasal 25 s.d. pasal 45 yang mengatur tentang pengembangan bahasa. Namun permasalahan saat ini hal demikian hanyalah aturan semata tanpa ada realisasinya dalam kehidupan dan juga pengajaran.

Dengan demikian hal ini menjadi daya tarik untuk diteliti, bahwa pembinaan dan pengembangan bahasa Indonesia dapat memberikan perencanaan, pengarahan, dan ketentuan-ketentuan yang dapat dipakai sebagai dasar bagi pengolahan keseluruhan masalah kebahasaan yang dihadapi oleh suatu bangsa secara nasional khususnya mahasiswa IAIN SNJ, sehingga bahasa dapat digunakan sebagaimana mestinya.

Pembinaan dan pengembangan bahasa adalah usaha dan kegiatan yang ditujukan untuk memelihara dan mengembangkan bahasa Indonesia supaya dapat memenuhi fungsi dan kedudukannya. Pembinaan dan pengembangan bahasa Indonesia dilakukan meliputi usaha-usaha pembakuan agar tercapai pemakaian bahasa yang cermat, tetap dan efisien dalam komunikasi. Untuk kepentingan praktis, telah diambil sikap bahwa pembinaan terutama ditujukan kepada penuturnya, yaitu masyarakat pemakai bahasa Indonesia, dan pengembangan terutama ditujukan kepada bahasa dalam segala aspeknya.

Pembinaan dan pengembangan mencakup dua arah yaitu pengembangan bahasa mencakup dua masalah pokok (masalah bahasa dan kemampuan/sikap) dan pembinaan juga mencakup dua arah (masyarakat luas dan generasi muda).

Masyarakat Indonesia terkhusus mahasiswa IAIN Syekh Nurjati Cirebon dianjurkan untuk menggunakan bahasa Indonesia dengan baik dan benar sesuai dengan lingkungan dan keadaan yang dihadapi benar sesuai dengan kaidah bahasa Indonesia. Tentu saja tidak terlepas dari tujuan pembinaan bahasa Indonesia, yaitu menumbuhkan dan membina sikap bahasa yang positif, dan meningkatkan kegairahan penggunaan bahasa Indonesia yang baik dan benar.

Sikap kesetiaan berbahasa Indonesia berungkap jika kita lebih suka memakai bahasa Indonesia dan menjaga agar pengaruh asing tidak berlebihan. Sikap kebanggaan berbahasa terungkap jika kita terdapat perasaan bahwa bahasa Indonesia dapat mengungkapkan konsep yang rumit secara cermat dan dapat mengungkapkan isi hati yang sehalus-halusnya. Hal ini, perlu ditegaskan karena di kalangan masyarakat terutama di mahasiswa berbagai sikap terhadap kemampuan berbahasa Indonesia, yaitu sikap positif bahasa Indonesia tidak berarti sikap kebahasaan yang kaku dan tertutup, menuntut kemurnian bahasa Indonesia dan menutup bahasa Indonesia dari hubungan saling pengaruh dengan bahasa lain yaitu bahasa daerah dan bahasa asing di Indonesia terhadap kurang lebih 400 bahasa daerah.

Pengguanaan bahasa yang baik dan benar adalah penggunaan yang disesuaikan dengan lingkungan dan pemakaian bahasa, diperoleh ragam bahasa, baik lisan maupun tulis. 
Penggunaan bahasa Indonesia dengan baik adalah pengguanaan ragam-ragam bahasa Indonesia sesuai dengan keadaan atau lingkungan komunikasi. Penggunaan bahasa Indonesia dengan benar adalah penggunaan yang disesuaikan dengan kaidah bahasa Indonesia. Dalam ragam tulis, kaidah itu tertera pada buku Pedoman Umum PUEBI, Pedoamn Umum Pembentukan Istilah, dan Tatabahasa Baku Bahasa Indonesia.

Sebagai masyarakat Indonesia khususnya kita dituntut berperan serta dalam meningkatkan mutu dan disiplin penggunaan serta penguasaan bahasa Indonesia. Hal ini perlu dilaksanakan agar penggunaan bahasa Indonesia sesuai dengan perkembangannya.

Upaya peningkatan mutu dan disiplin penggunaan bahasa Indonesia harus merupakan kegiatan yang berkesinambungan, baik pada tingkat perorangan maupun pada tingkat kemasyarakatan. Kita sebagai Pembina bahasa Indonesia hendaknya ikut berperan dalam mencapai tujuan pembinaan bahasa Indonesia. Kita sebagai bahasa Indonesia senantiasa menjaga, memelihara, dan mengembangkan agar masyarakat atau generasi ke depannya tetap bisa menggunakana bahasa Indonesia yang baik dan benar.

Penelitian ini didasarkan pada permasalahan yang berkaitan dengan analisis kesalahan penggunaan bahasa mahasiswa dan dosen pada UKM keprotokolan serta diskusi di kelas. Beberapa hasil penelitian terdahulu terkait dengan penelitian ini sebagai berikut:

Penelitian relevan yang pertama dilakukan oleh Rosida, dkk (2019). Tujuan penelitian ini yaitu kesadaran pentingnya kegiatan $\mathrm{MC}$ dan keprotokolan sehingga dapat meningkatkan kualitas kegiatan MC dan keprotokolan yang dilakukan, serta dapat memberi bekal keterampilan tentang bagaimana kegiatan MC dan keprotokolan harus dilaksanakan.
Sehingga dalam penyelenggaraannya perlu dikelola supaya acara berlangsung lancar dan sesuai dengan etika kantor. Penelitian ini lebih menekankan pada aspek wawasan sistematis protokoler belum memadai, menyusun susunan acara dinilai kurang bagus, intonasi dan volume suara kurang tepat.

Penelitian relevan yang kedua, penulisnya adalah Dina Almiati (2019). Penelitian ini menganalisis komunikasi dalam protokoler. Pentingnya berkomunikasi melalui $\mathrm{MC} /$ keprotokolan untuk memberikan kesadaran dan pemahaman tentang peran penting berbicara di depan orang banyak.

Penelitian relevan yang ketiga, penulisnya adalah Julistia dan Rachman (2014). Penelitian ini menganalisis tentang komunikasi korps protokoler dalam lingkup kalangan kampus UNISBA. Analisis utamanya berkaitan dengan komunikasi serta penggunaan bahasa pada keprotokolan.

Penelitian relevan yang keempat, penulisnya adalah Puput Islamitha Lukman (2017). Penelitian ini ingin mengetahui dan mendeskripsikan pelaksanaan kode etik protokol pada staff protokoler. Yang menjadi analisis utamanya pada tata laksana tugas humas dan keprotokolan di Universitas Mulawarman Samarinda.

Penelitian relevan yang kelima, penulisnya adalah Desy Purnamayani (2014). Yakni terkait analisis kesalahan pembahasaan pada Diskusi di kelas. Namun yang membedakan dengan penelitian kami yakni objek samplenya.

Penelitian relevan yang keenam, penulisnya adalah Sarah Apriani (2018). Kajian ini meneliti tentang penggunaan Bahasa Indonesia pada diskusi di kelas dengan objek kajian siswa SMA.

\section{METODE}

Penelitian ini dilakukan dengan menggunakan metode simak dan metode 
cakap. Metode simak merupakan cara untuk memperoleh data dengan menyimak penggunaan bahasa, atau cara serta karakter berbicaranya. Metode simak ini memiliki teknik dasar yang berwujud teknik sadap dikarenakan pada hakikatnya penyimakan diwujudkan dengan penyadapan. Dalam arti, peneliti dalam upaya mendapatkan data dilakukan dengan menyadap penggunaan bahasa dan cara berbicaranya seseorang atau beberapa orang yang menjadi informan. Seperti halnya yang dilakukan peneliti dengan menyadap atau menyimak pemakaian bahasa dan cara yang digunakan oleh Mahasiswa IAIN Syekh Nurjati dan sebagian Dosen IAIN Syekh Nurjati Cirebon yaitu . Dengan metode simak teknik sadap tersebut peneliti dapat memperoleh data bahasa dan cara berbicara serta karakter dari mahasiswa tersebut sehingga peneliti sedikitnya bisa memberikan solusi (pengembangan dan pembinaan) supaya para mahasiswa bahkan dosen bisa membiasakan dirinya menggunakan bahasa Indonesia sesuai kaidah ketatabahasaan.

Namun dalam metode simak selain teknik sadap ada juga teknik kedua yaitu teknik catat dan rekam. Teknik catat dan rekam adalah teknik lanjutan yang dilakukan ketika menerapkan metode simak. Dengan melakukan pencatatan dan rekaman, si peneliti dapat menyimpan data-data yang kemudian hari akan ditinjau kembali. Dengan teknik catat dan rekam ini dijadikan sebagai alat terwujudnya kelancaran suatu penelitian. Selanjutnya metode yang dilakukan peneliti dalam mengumpulkan data ialah dengan menggunakan metode cakap. Metode cakap adalah metode atau cara yang ditempuh dalam pengumpulan data berupa percakapan antara peneliti dengan informan (forum diskusi). Seperti yang dilakukan peneliti yaitu pada saat diskusi di kelas dengan teman-temannya yang sedang melaksanakan presentasi.

\section{HASIL DAN PEMBAHASAN}

\begin{tabular}{|c|c|c|c|c|c|}
\hline z & Informan & है & Tempat & $\begin{array}{c}\text { Waktu } \\
\text { Penelitian }\end{array}$ & $\begin{array}{c}\text { Bahasa } \\
\text { yang } \\
\text { digunakan }\end{array}$ \\
\hline 1 & $\begin{array}{l}\text { Sebagian } \\
\text { anggota } \\
\text { UKM Korps } \\
\text { Protokoler } \\
\text { Mahasiswa }\end{array}$ & . & $\begin{array}{l}\text { Di } \\
\text { Berbagai } \\
\text { tempat } \\
\text { contohnya } \\
\text { di SBSN. }\end{array}$ & $\begin{array}{l}\text { Ketika ada } \\
\text { acara khusus } \\
\text { KPM. }\end{array}$ & $\begin{array}{l}\text { Bahasa } \\
\text { Indonesia } \\
\text { namun tidak } \\
\text { sesuai } \\
\text { dengan } \\
\text { PUEBI } \\
\end{array}$ \\
\hline $\begin{array}{l}2 \\
.\end{array}$ & $\begin{array}{l}\text { Sebagian } \\
\text { Mahasiswa } \\
\text { kelas A } \\
\text { Tadris } \\
\text { Bahasa } \\
\text { Indonesia } \\
\text { IAIN Syekh } \\
\text { Nurjati } \\
\text { Cirebon } \\
\text { semester V1 }\end{array}$ & . & $\begin{array}{l}\text { Di Kelas } \\
\text { pada saat } \\
\text { presentasi } \\
\text { kelompok }\end{array}$ & $\begin{array}{l}\text { Sabtu, 17 } \\
\text { Juni 2019 } \\
\text { pukul 07:30 } \\
\text { pagi }\end{array}$ & $\begin{array}{l}\text { Bahasa } \\
\text { Indonesia } \\
\text { namun } \\
\text { masih } \\
\text { terbawa } \\
\text { bahasa } \\
\text { kedaerahann } \\
\text { ya dan } \\
\text { kurang } \\
\text { sesuai } \\
\text { dengan } \\
\text { kaidah } \\
\text { ketatabahasa } \\
\text { an } \\
\end{array}$ \\
\hline $\begin{array}{l}3 \\
\text {. }\end{array}$ & $\begin{array}{l}\text { Salah satu } \\
\text { Dosen IAIN } \\
\text { Syekh } \\
\text { Nurjati } \\
\text { Cirebon }\end{array}$ & 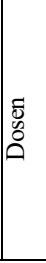 & Kelas & $\begin{array}{l}\text { Ketika mata } \\
\text { kuliah } \\
\text { berlangsung } \\
\text { pada saat } \\
\text { menyampai } \\
\text { kan materi. }\end{array}$ & $\begin{array}{l}\text { Bahasa } \\
\text { Indonesia } \\
\text { namun lebih } \\
\text { mempriorita } \\
\text { skan bahasa } \\
\text { asing yaitu } \\
\text { bahasa } \\
\text { Inggris. }\end{array}$ \\
\hline
\end{tabular}

\section{Sebagian anggota UKM Korps Protokoler Mahasiswa}

Pekan lalu, pada saat acara buka bersama dan open house halal bi halal UKM korps Protokoler Mahasiswa IAIN Syekh Nurjati Cirebon, peneliti menemukan berbagai masalah kebahasaan pada pembawa acara atau master of ceremony yang menurut peneliti sendiri hal itu melanggar kaidah ketatabahasaan bahasa Indonesia.

\section{Contoh 1 : Pada kata yang terhormat dan yang kami hormati}

Kesalahan yang terjadi ini terdapat pada saat opening atau pembukaan acara berlangsung, yang tidak sesuai dengan PUEBI, yaitu pada penggunaan kata yang terhormat dan yang kami hormati.

MC : "Kepada yang terhormat Bp. Dr. H. Sumanta M.Ag beserta yang 
terhormat bapak pembina KPM bpk. Badaruddin"

Analisisnya kata yang terhormat yang dituturkan si pembawa acara tersebut digunakan sama kepada rektor dan pembina UKM KPM, sehingga terjadi kesamaan jabatan antara keduanya, padahal kata ter- menurut PUEBI itu memiliki arti paling, sehingga jika peneliti analisis kata ter-hormat itu digunakan hanya untuk kepada orang yang memiliki jabatan paling tinggi di suatu lembaga tersebut.

Sehingga seharusnya yang harus dituturkan oleh pembawa acara pada saat memimpin acara yaitu dengan kalimat "Selamat siang dan selamat datang kami ucapkan kepada yang terhormat Bp. Dr. H. Sumanta M.Ag beserta yang kami hormati bapak pembina UKM KPM IAIN Syekh Nurjati Cirebon bpk. Badaruddin". Dengan demikian dapat terlihat jelas perbedaannya antara orang yang memiliki jabatan paling tinggi dengan orang yang berada di bawahnya.

\section{Contoh 2 : Pada kata waktu dan tempat kami persilahkan}

MC : "Sambutan dari ketua UKM Korps Protokoler IAIN yekh Nurjati Cirebon Bpk Badarudin, waktu dan tempat kami persilahkan"

Berdasarkan apa yang telah peneliti analisis kata waktu dan tempat serta kata persilahkan itu sangat melanggar kaidah ketatabahasaan serta PUEBI. Alasannya karena waktu dan tempat itu tidak bisa dipersilakan melainkan yang harus dipersilakan itu adalah orangnya bukan waktu dan tempatnya. Jadi yang harus di tuturkan oleh pembawa acara yaitu "Sambutan dari ketua UKM Korps Protokoler IAIN yekh Nurjati Cirebon, yang kami hormati Bpk Badarudin, kepadanya kami persilakan".

Selain itu harus dicermati juga kita sebagai bangsa nasionalis harus faham betul akan PUEBI karena kata persilahkan secara PUEBI nya yaitu persilakan, jadi konsonan $h$ - nya dibuang.

Contoh 3 : pada kata untuk mempersingkat waktu dan sodarasodara

MC : "Untuk mempersingkat waktu, marilah sodara-sodara untuk sejenak mendengarkan lantunan ayat suci alquran"

Pada kata mempersingkat waktu dan sodara-sodara itu terlihat sekali melanggar kaidah bahasa, berdasarkan PUEBI karena waktu itu tidak bisa disingkat, melainkan waktu itu hanya bisa dihemat bukan disingkat. Selain itu kata yang harus diperbaiki yaitu pada kata sodara yang kerap sekali sering dituturkan oleh para protokoler, hal demikian harus diubah karena secara PUEBI kata yang benar adalah saudara-saudara bukan sodara sodara.

Jadi seharusnya : "Untuk mengevesiensikan waktu, marilah saudara-saudara untuk sejenak mendengarkan lantunan ayat suci alquran berikut"

\section{Contoh 4 : pada kata menginjak acara berikutnya}

Kata menginjak ini memang secara PUEBI benar adanya, namun biasa diguakan untuk kalimat jangan menginjak rumput, jadi penempatan tempat suatu kalimatnya kurang efektif. Sehingga ketika di acara seharusnya digunakanlah kata Masuk ke acara berikutnya atau bisa saja dengan kata yang sederhana yaitu acara selanjutnya adalah. Sehingga tidak terkesan rancu.

\section{Contoh 5 : Pada kata mohon maaf} ababila ada salah-salah kata

MC menutup acara berikut dengan kalimat "mohon maa apabila ada salahsalah kata".

Kesalahan tersebut terdapat pada kata salah yang diulang dua kali, 
sebenarnya kata salah tersebut adalah kata keterangan yang tidak usah diungkapkan dua kali, justru kata-katanya yang memang tepat diulang dua kali. Menjadi "mohon maaf apabila ada kata-kata yang salah".

Dari hal tersebut, dapat peneliti lihat bahwa penggunaan bahasa Indonesia dengan baik dan benar di kalangan anggota protokoler yaitu kurang sesuai dengan PUEBI dan kaidah bahasa lainnya, sehingga kedepannya ketika ada publik figur yang sering mengungkapkan tuturan tersebut sehingga tuturan yang diucapkan beliau sudah familier atau bahkan terkenal jangan langsung dijiplak atau diikuti, harusnya dianalaisis dan diteliti terlebih dahulu apakah sudah sesuai dengan PUEBI atau tidak sehingga tidak menduplikasi generasi lainnya.

\section{Sebagian mahasiswa kelas A Tadris Bahasa Indonesia IAIN Syekh Nurjati Cirebon semester V1}

Pada hari Sabtu, 17 Juni 2019 pukul 07:30 pagi, sebagian mahasiswa kelas A Tadris Bahasa Indonesia IAIN Syekh Nurjati Cirebon semester V1 melaksanakan proses diskusi di mana ada penyaji dan ada pula audiensi. Mereka saling berkolaborasi dan bertukar pikiran antara yang satu dengan yang lainnya sehingga menghidupkan suasana diskusi tersebut.

Namun sayangnya dari bahasa pengantar yang mereka gunakan masih terdapat beberapa kalimat yang setiap katanya diungkapkan dengan bahasa daerahnya masing-masing seperti kien yang berasal dari Bahasa Jawa, kata mah yang berasal dari bahasa Sunda dan masih banyak lagi bahasa yang mereka lontarkan yang selalu dicampuri dengan bahasa asalnya. Sehingga dapat peneliti simpulkan bahwa masih banyak mahasiswa yang kental akan daerahnya sehingga lupa akan bahasa nasionalnya yang baik dan benar itu seperti apa.
Karena hal demikian, faktor penyebabnya bisa saja dengan kurangnya minat baca terhadap pembelajaran bahasa Indonesia, serta kurangnya pembiasaan diri sejak dini bahkan kurangnya pembinaan dari keluarganya serta guru sekolahnya sehingga ketika di perguruan tinggi pun mencetak gol hasil cetakannya seperti itu.

\section{Salah satu Dosen IAIN Syekh Nurjati Cirebon}

Ketika mata kuliah berlangsung pada saat menyampaikan materi, salah satu Dosen IAIN Syekh Nurjati Cirebon selalu menggunakan bahasanya dengan bahasa yang ia kuasainya yaitu dengan bahasa asingnya (bahasa Inggris), sehingga timbul keresahan peserta didik yang memang kurang memahami dan mengetahui instruksi apa yang seharusnya peserta didik itu lakukan.

Memang kita juga sebagai generasi bangsa harus menguasai bahasa lain termasuk bahasa Inggris, namun tidak melupakan bahasa kita bahasa Indonesia, terlihat oleh peneliti dosen tersebut selalu menyampaikan materi itu memprioritaskan bahasa Inggrisnya dibandingkan bahasa nasionalnya, sehingga yang lebih dominan itu adalah bahasa asingnya.

Timbulah kekhawatiran peneliti, ketika semua dosen seperti itu, ditakutkan bahasa nasional kita sedikit demi sedikit larut dengan sendirinya bahkan luntur akibat kurang digunakan. Seharusnya kita sebagai warga Indonesia harus bisa memilih dan memilah atau bahkan bisa menyesuaikan diri bahasa apa yang perlu kita gunakan ketika kegiatan itu berlangsung.

Dari beberapa permasalahan tersebut, pemerintah sebaikanya melakukan tindak lanjut yang dapat meningkatkan mutu pengajaran bahasa Indonesia di semua jenis dan jenjang pendidikan. Hal ini dapat dimulai dengan 
meningkatkan kempampuan guru atau dosen bahasa Indonesia, pengembangan bahasa Indonesia yang sesuai dengan komunikatif dan integratif bahasa, kebudayaan serta penalaran, bahkan pemberian pengalaman belajar kepada siswa.

Selain itu, memantapkan kedudukan dan fungsi bahasa Indonesia sebagai sarana pendidikan dan pengajaran, serta pola kebijaksanaan nasioanal kebahasaan harus disusun. Hal ini dapat dilakukan dengan penentuan starategi pengajaran, pengembangan tata bahasa, penggunaan tatabahasa yang baik dan benar yang sesuai dengan PUEBI, kemantapan kemampuan berbahasa Indonesia sebagai persyaratan untuk berbagai macam kenaikan pangkat dan tingkat.

Hal itu pula sebagai penunjang pembinaan bahasa Indonesia di kalangan mahasiswa harus memiliki bahan pelajaran bahasa Indonesia yang mencakup menyimak, berbicara, menulis dan membaca. Pembinaan dan pengembangan bahasa Indonesia hendaknya memanfaatkan organisasi profesi dan lembaga kemasyarakatan.

\section{KESIMPULAN}

Sebagian mahasiswa dalam dunia keprotokolan dan proses diskusi bahkan dosen dalam penyampaian materi dalam penggunaan bahasa Indonesianya masih terbilang, hal ini dapat dilihat dari tuturannya yang dikaitkan dengan kaidah bahasa yaitu PUEBI sehingga masih diperlukannya pembinaan dan pengembangan bahasa Indonesia guna mencetak generasi bangsa yang cinta akan tanah air kita.

\section{DAFTAR PUSTAKA}

Ahdiyana, M. (2019). Persiapan Menjadi $M C$. Yogyakarta : Universitas Negeri Yogyakarta.

Alamianti, D., Yudhakusuma, D., \& Mukhlisiana, L. (2019).

PELAKSANAAN MC DAN
KEPROTOKOLAN DALAM
MENGEMBANGKAN
KEMAMPUAN
BERKOMUNIKASI. DIALEKTIK
A, 6(1), 89-94.

Anita, W. (2011). Tata Bahasa Baku Bahasa Indonesia. Jakarta: Balai pustaka.

BAM, S. A., Setiawan, B., \& Saddhono, K. (2018). PENGGUNAAN BAHASA INDONESIA PADA DISKUSI SISWA SMANEGERI 4 SURAKARTA: KAJIAN DENGAN PRINSIP KERJA SAMA GRICE DAN RELEVANSINYA SEBAGAI BAHAN AJAR KETERAMPILAN BERBICARA. Basastra: Jurnal Bahasa, Sastra, dan Pengajarannya, 6(1), 281-301.

Balawa, L. O. (2010). Pembinaan dan Pengembangan Bahasa. Kendari : FKIP Unhalu.

Lukman, P. I. (2017). ANALISIS PELAKSANAAN KODE ETIK PROTOKOL PADA STAF PROTOKOLER HUMAS UNIVERSITAS

MULAWARMAN. eJournal Ilmu Komunikasi Volume 5, Nomor 2, 2017 : 189-199.

Hamalik, O. (2013). Proses Belajar Mengajar. Jakarta: PT Bumi

Aksara. H. M., Junaiyah. (2014). Pembinaan dan Pengembangan Bahasa Indonesia. Tangerang : PT Pustaka Mandiri.

Julistia, R. (2014). Pola Komunikasi Anggota Korps Protokoler Mahasiswa UNISBA dalam Membangun Reputasi Kampus Studi Kualitatif dengan Pendekatan Studi Kasus Korps Protokoler dalam Membangun Reputasi Kampus Universitas Islam Bandung (Doctoral 
dissertation, Fakultas Ilmu $\mid$ Nasution.2013. Berbagai Pendekatan Komunikasi Universitas Islam Bandung (UNISBA)). Dalam Proses Belajar Mengajar. Jakarta: PT Bumi Aksara.

Kosasih, E. (2003). Ketatabahasaan dan Kessusastraan. Bandung : CV Yrama Widya.

Mahsun. (2005). Metode Penelitian Bahasa. Jakarta: PT Raja Grafindo Persada.

Muslich, M. (2010). Bahasa Indonesia Pada Globalisasi: Kedudukan, Fungsi, Pembinaan dan Pengembangan. Jakarta: Bumi Aksara

Purnamayani, N. M. D., Sudiara, I. N. S., \& Sriasih, S. A. P. (2014). Analisis Kesalahan Bahasa Diskusi dalam Pembelajaran Bahasa Indonesia Siswa Kelas XI di SMA Negeri 1 Sukasada. Jurnal Pendidikan Bahasa dan Sastra Indonesia Undiksha, 2(1).

Sagala, Syaiful. (2006). Konsep dan Makna Pembelajaran. Bandung: Alfabeta. 